\title{
Robotic Education in 21st Century: Teacher Acceptance of Lego Mindstorms as Powerful Educational Tools
}

\author{
Mardhiah Masril ${ }^{1}$, Ambiyar ${ }^{2}$, Nizwardi Jalinus ${ }^{3}$, Ridwan $^{4}$, Billy Hendrik ${ }^{5}$ \\ Dept. Faculty of Computer Science, Universitas Putra Indonesia "YPTK" Padang, Padang, Indonesia ${ }^{1,5}$ \\ Dept. Faculty of Engineering, Universitas Negeri Padang, Padang, Indonesia, ${ }^{1,2,3,4}$ \\ Dept. Institute IR 4.0, Universiti Kebangsaan Malaysia, Bangi, Malaysia ${ }^{5}$
}

\begin{abstract}
Acceptance of robotic technology in education is a crucial issue in the revolution industry 4.0 era. This study aims to explore the acceptance of Lego Mindstorms Ev3 as one kind of robotic technology by the teachers as a learning resources that can develop teachers and student's skills. The Technology Acceptance Model (TAM) was introduced by using questionnaires. The questionnaires were responded by 22 elementary school teachers who have experiences with Lego Mindstorms ev3 kits in a workshop. The data was carried out by presenting descriptive statistics, correlation, and regression analyses. Based on the acceptance testing of Lego Mindstorms Ev3 with the TAM model, the result showed that subjective norms (SN) and self-efficacy (SE) as external variables were effective on the acceptance of Lego Mindstorms Ev3 as a learning tools by teachers. Teacher's SN have a positive correlation with perceived usefulness (PU), perceived ease to use (PE), and behavioral intention to use (BI). Teacher's self-efficacy were significant in predicting PE and BI. PU and PE had a positive effect on Attitude toward using Lego Mindstorms Ev3 by teachers, and it continued to use. Finally, most teachers have shown positive reactions to Lego Mindstorms Ev3 as educational tools.
\end{abstract}

Keywords-Education; TAM; teacher acceptance; Lego; Robotic

\section{INTRODUCTION}

The Acceptance of technology in the educational sector as innovative learning tools has become a favorite topic for exploration in a recent years. Learning tools have an important role in achieving the learning objectives especially technologybased learning tools [1], even technology-based teaching and learning facilities have an important role in transforming education [2]. One of the innovative learning tools in the industrial revolution 4.0 era is robotic technology. Most individuals seem to agree that robotics as a learning tool has provided many benefits in improving cognitive abilities, creative thinking skills [3], [4], problem-solving skills, collaboration skills, STEM, and computational thinking of students [5], [6]. There are many benefits of applying robotic technology in schools; therefore, introducing this technology early to students is important. The current students are Zgeneration and alpha-generation, they are very easy to accept and adapt to the robotic technology that has been applied in their learning processes in the classroom. Student's acceptance of robotic technology in education has been demonstrated in previous research, students preferred to ask a robot about the information they wanted to know rather than ask an adult [7], students were more likely to followed behavioral suggestions offered by an autonomous social robot [8], the students familiar and had positive attitudes towards social robots (Fanuc LR Mate 200 ID, Sputnik, Nao) [9]. In addition to social robots, one of the educational robots that have high interaction with students is Lego. Lego is a kind of robotic technology widely used in the teaching-learning process [10]. In previous studies about student's acceptance of Lego Mindstorms, the young students (11-18 years) were more receptive to Lego Mindstorms in the learning process than the old students (1924 years) [11], the early adolescents perceived educational and learning of robotics (Lego Mindstorms) as a source of employment, and as a way to high technology [12]. But teacher's acceptance of robotic technology also needs to be explored.

The teacher's acceptance of robotic technology as learning tools was very important to analyze because (1) The effective use of technology in classrooms is based on the attitudes of teachers to technology. Previous studies have shown that the attitudes of teachers, as well as expertise and skills in the use of technology, major factors influencing their initial adoption of technology and their future computer use actions [13]. The effectiveness of a teaching method is closely related to how teachers able to use technology to engage the learners [14]. Teachers' acceptance of technology is an important factor that influences the teacher's teaching method, teachers' behavior in the classroom and influences students' learning as well [15]; (2) robotic technology as innovative learning tools would not be effective if the teachers were not able to use it properly, a generation gap between teachers and students resulted in the teachers were more difficult to adapt to new technologies than students, the main characteristic differences among $\mathrm{X}, \mathrm{Y}$, and Z- generations are the mastery of information and technology; (3) Besides, teachers are responsible for ensuring that the technologies work correctly [16], demonstrating their added value in the teaching process, and offering a wider view of the purpose and significance of using technology.

\section{A. Technology Acceptance Model}

The Technology Acceptance Model (TAM) has become the most generally accepted theoretical paradigm for the acceptance of research technology. Introduced by Davis

*Corresponding Author 
(1989), TAM was an evolution of the "Theory of Reasoned Action" [13]. TAM is a blueprint for how it will be adopted and used by technology users [17]. Another opinion said that TAM gave a recommendation when people use new technology for their activity based on usefulness and ease to use, this recommendation will influence their decision, accepting or rejecting it [18]. Original TAM by Davis [19] is shown in Fig. 1.

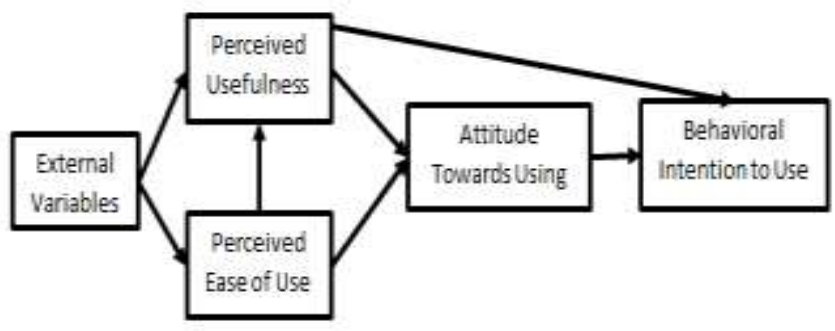

Fig. 1. Technology Acceptance Model (TAM).

Original TAM consists of two key variables (1) perceived ease of use (PE); (2) perceived usefulness (PU) [20], while attitude towards using, behavioral intention to use, and actual usage of the device are the deciding variables of technology acceptance [14], [21], [22], [23].

PU indicates the degree to which a person believes his/her success will be improved by the use of a system [14], [17]. PE indicates the degree of ease of use of the technology if the technology is too difficult to use, instead of using new technology, users will find the alternative form [17], [21]. PU and PE decide users' attitudes towards technology [24], [25], PU, and AT have a direct influence on behavioral purpose to use (BI) [19]. Intention to use is determined by attitudes and usefulness, and intention to use has a relationship with actual use [26], it can be determines, technology acceptance [27]. Several researchers have replicated Davis's original model [28] and added external variables to the model.

In this analysis, TAM was selected as the research model because it can assess the effect of external variables on perceptions, intention to use, and TAM as the best model for predicting user behavior towards new technology [29]. It was in accordance with this study which aims to determine the external factors that affect the behavior intention of teachers in using robotic technology in their class.

\section{B. Acceptance of Robotic Technology by Teachers}

Previous studies have been conducted on teacher acceptance for robotic technology, the potential benefits of the movements of the robot, and the significant correlation between changes in familiarity and perception in human-robot interaction have been identified [30]. The Thymio Robot application has high usability, teachers are very interested and have a desire to learn and master the use of the Thymio robot, through understanding new technologies, develop teacher professionals [10]. Teachers' ability to use robotic technology in training will enhance skills, self-confidence, and interactions between teacher and student, leading to a willingness to implement educational robotics in schools, this research shows the value of high-quality professional development in the selfefficacy of educators with the use of Educational Robotics, and suggests that new tablet-based wireless robotics platforms, such as LEGO® WeDo 2.0, enable younger learners to engage with this technology [31]. Another study reported that usage of WeDo as a robotics kit in the teaching-process helped the teachers build their confidence and knowledge to introduce students to computational thinking [32]. Reich-Stiebert explored the ability of teachers to use robots in different learning settings in a German survey of 59 teachers. Their findings revealed teachers' very negative attitude toward educational robots. The authors concentrated on the robot NAO as an assistant to teachers in this report. The research was distinguished by age, gender and subject taught. There was no major effect of age and gender on attitudes. The topic taught, however, had a substantial impact: teachers chose to use robots in STEM-related domains [33].

\section{Objectives of the Present Study}

Few studies have reported on Lego / robotic technology acceptance in the learning process, but the majority of studies focused on students' interaction with robotic technology in the classroom. Teachers' acceptance more discussed robots as an assistant of a teacher in the classroom, and very little information available on teachers' acceptance of Lego Mindstorms Ev3 as learning practices in the classroom while Lego practices were widely used in the teaching-learning process.

The purpose of this study was to explore the teachers' acceptance of robotic technology, especially Lego Mindstorms Ev3 as learning tools by elementary school teachers. To evaluate the teacher's acceptance, we used the Technology Acceptance Model (TAM) with external variables were subjective norm and self-efficacy (adopted by Yuen, 2008).

The behavioral decisions or intentions of individuals are always influenced by the other people around them [34]. The subjective Norm, a person's subjective norm is his or her perception that most people who are important to him or her think he or she should or should not perform the behavior in question [13]. Theory of Reasoned Action claimed that motivation to comply (known as compliance) is a predictor for subjective norms, and subjective norms are a predictor for intentions [35]. Subjective norm is one of the main variables in the Theory of Planned Behavior (TPB) [36] that can influence behavioral intentions in IT adoption.

Self-efficacy and technology have a strong relationship. Bandura defines self-efficacy as "People's judgments of their capabilities to organize and execute courses of action required to attain designated types of performances [37]. High-self efficacy can aid individuals in initiating cross-cultural interactions, persisting in the face of early failures, and engaging in problem-solving as a way of mastering necessary skills [38]. Self-efficacy is one of the key drivers of human activity and it has been found to have both direct and indirect impact on the intention and actual use of different technologies [39]. Self-efficacy can have effects on individual intentions [40], individual engagement, and behavior.

The result of this study could be useful to help teachers adopting Lego Mindstorms Ev3 for their teaching practices, may provide information on how teachers accept robotics 
technology as a learning tool in schools, and improve educational sectors to adapt to technological developments.

\section{Hypothesis}

Based on Fig. 1, the following hypotheses of this study:

H1: The perceived ease of use (PE) has a positive effect on the perceived usefulness (PU) of Lego Mindstorms Ev3 as educational tools by teachers.

H2: The perceived ease of use (PE) and the perceived usefulness (PU) have a positive effect on the Attitude toward using (AT) of Lego Mindstorms Ev3 as educational tools by teachers.

H3: The perceived usefulness (PU) and attitude toward using (AT) have a positive effect on the behavioral intention to use (BI) of Lego Mindstorms Ev3 as educational tools by teachers.

H4: The Subjective norm (SN) has a positive effect on the perceived usefulness (PU) of Lego Mindstorms Ev3 as educational tools by teachers.

H5: The Subjective norm (SN) has a positive effect on the perceived ease of use (PE) of Lego Mindstorms Ev3 as educational tools by teachers.

H6: The Subjective norm (SN) has a positive effect on the behavioral intention to use (BI) of Lego Mindstorms Ev3 as educational tools by teachers.

H7: The Self-efficacy (SE) has a positive effect on the perceived usefulness (PU) of Lego Mindstorms Ev3 as educational tools by teachers.

H8: Self-efficacy (SE) has a positive effect on the perceived ease of use (PE) of Lego Mindstorms Ev3 as educational tools by teachers.

H9: Self-efficacy (SE) has a positive effect on the behavioral intention to use (BI) of Lego Mindstorms Ev3 as educational tools by teachers.

\section{METHODOLOGY}

\section{A. Procedure}

1) Teachers actively interacted with Lego Mindstorm Ev3 in a workshop (attending 2 days of workshop).

2) After the workshop was completed, the teachers were asked to fill out a questionnaire related to teachers' acceptance of the use of Lego Mindstorm Ev3 as learning tools.

3) To evaluate the teacher's acceptance, we used the Technology Acceptance Model (TAM) developed by Davis (1989).

4) The reliability test used Cronbach's alpha for each item, the alpha value is at least 0.7 and higher, it was mean reliable [41].

5) Analyzing the data descriptive statistic to determine the minimum, maximum, average, and standard deviation values.

6) Hypothesis testing used regression analysis.

7) Data analysis was performed with SPSS software.

\section{B. Participant}

Participants in this study consisted of 22 teachers from five elementary schools in Padang, West Sumatra, Indonesia, who had attended a workshop on robotic technology. The teacher's characteristics can be seen in Table I.

\section{Workshop of Robotic for Teacher}

This workshop has been held for elementary school teachers, so that teachers could interact directly with Lego Mindstorms Ev3 as learning tools in this workshop so that teachers can ensure ease of use and benefit for teachers and students in the learning process. Lego Mindstorms offers an environment for teachers and students to interact in an exciting, creative way [42]. The workshop was held for 2 days; detailed activities are shown in Table II.

The first section, the introduction of robotic technology, the implementation of robotic technology especially in the education sector, and the benefits of applying robotic technology for students. Information presented to teachers via an interesting audio visual media, these activities focused on gave deeper knowledge of robotic technology.

The clarification preceded by getting to know the Lego Mindstorms Ev3 as the methods to be used in this workshop as an experiment. The components of the Lego Mindstorms Ev3 package and the tasks of each of these components are introduced to the teacher. Lego Mindstorms Ev3 consist of building kits and a programmable control unit that can allow a robot to be built. This kit includes all essential components, such as connectors, axles, bushings, beams, frames, tubes, gears, belts, shafts, wheels, motors, sensors, and control centers, necessary for the construction of a robot [4]. After this section, the teachers were able to understand the function of Lego Mindstorm Ev3 kits.

TABLE I. DEMOGRAPHY TABLE OF PARTICIPANT

\begin{tabular}{|l|l|l|}
\hline Characteristic & Value & Frequency \\
\hline \multirow{3}{*}{ Age } & $<30$ & 3 \\
& $30-35$ & 11 \\
\multirow{2}{*}{ Gender } & $>35$ & 8 \\
\hline
\end{tabular}

TABLE II. ACTIVITIES OF ROBOTIC TECHNOLOGY WORKSHOP

\begin{tabular}{|l|l|c|}
\hline Sections & Activities & Duration \\
\hline Section 1 & $\begin{array}{l}\text { Introduction of robotic technology } \\
\text { and Lego Mindstorms Ev3 kits. }\end{array}$ & $\begin{array}{l}\text { (at 08.00 am to 11.50 } \\
\text { am on the first days) }\end{array}$ \\
\hline Section 2 & $\begin{array}{l}\text { Project 1 - Create Tracker Tank } \\
\text { Bot }\end{array}$ & $\begin{array}{l}\text { (at 01.00 pm to 05.00 } \\
\text { pm on the first days) }\end{array}$ \\
\hline Section 3 & $\begin{array}{l}\text { Project 2 - Create humanoid robot } \\
\text { Ev3rstorm }\end{array}$ & $\begin{array}{l}\text { (at 08.00 am to 11.50 } \\
\text { am on the second days) }\end{array}$ \\
\hline Section 4 & $\begin{array}{l}\text { Project 3 - Create the robots based } \\
\text { on teacher's creations }\end{array}$ & $\begin{array}{l}\text { (at 01.00 pm to 05.00 } \\
\text { pm on the second days) }\end{array}$ \\
\hline
\end{tabular}


In the second section, via the Lego Mindstorms Ev3 kits, the teachers were able to get new experiences. The search for teachers to create groups started with this segment (a group consisting of two teachers). A Tracker Tank Bot was developed for the project-1, this project started with how to design, develop, build, before how to control a Tracker Tank Bot. In the third segment, each group of teacher's plan, create, build, and learn how to program Brick as a control center in Lego Mindstorms Ev3 in project-2. A programme for controlling sensors (color, ultrasonic, contact, infrared, gyro, temperature sensor) [43], and motors can be sent by the brick as the robot actuator.

The teachers were asked to make robots based on their creations in the last sections of project-3, this activity offered the teachers an opportunity to develop their ideas to build a new robot or change a robot through Lego Mindstorms Ev3.

\section{Instrument}

The questionnaires were used to obtain information for this quantitative study. The instrument of questionnaire adopted by prior studies and modified to be compatible with this study context. The questionnaire was consist of 19 items, four items for perceived usefulness (PU), four items for perceived ease to used, three items for attitude (AT), four items for intention to use (BI), were adopted from Davis [44], and Çukurbaşı [45]. Two items for subjective Norm (SN), and two items for selfefficacy (SE), were adopted from Yuen [13], Bröhl [28], and Nadlifatin [36]. All items were measured in a 5-point Likert Scale with 1 as "strongly disagree" and 5 as "strongly agree". Details of all items used in the questionnaire are provided in Appendix A.

\section{RESULT}

This section has presented the results of descriptive statistics, correlation analysis, and regression analysis. Cronbach's alpha was calculated to test reliability (an alpha of at least 0.7).

According to Table III, all items of questionnaire were reliable, these were indicated by alpha coefficient 0.890 . Correlation between variables were presented in Table IV and Fig. 2.

Table IV presented high correlation between $\mathrm{SN}$ and BI (0.843), medium correlation between: PE and AT (0.620); PU and AT (0.573); AT and BI (0.580); SN and PU (0.438); SN and PE (0.561); SE and PE (0.544); SE and BI (0.527), no correlation between PE and PU; PU and BI; SE and PU.

According to Table V, a p-value of PE to PU $=0.064>$ 0.05 , indicated that PE has not had a positive effect on PU of Lego Mindstorms Ev3 as learning tools. This means that the ease of using Lego Mindstorms Ev3 as learning tools has no effect on the perceived benefits of teachers in the learningprocess (H1 was rejected).

PE and PU simultaneously to AT showed a p-value of $0.001>0.05$, B-value of $\mathrm{PE}=0.372$ and $\mathrm{PU}=0.341$, it indicated the perceived ease of use (PE) and the perceived usefulness (PU) have positive effect on the Attitude toward using (AT) of Lego Mindstorms Ev3 as educational tools by teachers. Rated $\mathrm{R}=0.714$ with a coefficient of determination
$(\mathrm{R}-$ Square $)=0.510$, it could be stated that the PE and PU influence the AT of $51.0 \%$, it can be stated that if Lego Mindstorms Ev3 as learning tools easier to use and the greater the benefits in the teaching and learning process in the classroom, the teachers are more able to accept LEGO Mindstorms Ev3 as learning tools (H2 was accepted).

B-value of AT $=0.965$ and PU $=-0.091$, partially AT has a positive effect on BI while PU has not had a positive effect on BI, but PU and AT simultaneously to BI presented p-value of $0.019<0.05$, it indicated the perceived usefulness (PU) and attitude toward using (AT) have positive effect on the behavioral intention to use (BI) of Lego Mindstorms Ev3 as educational tools by teachers. Rated $\mathrm{R}=0.583$ with a coefficient of determination (R-Square) $=0.340$, it could be stated that the PU and AT influence the BI of $34.0 \%$ (H3 was accepted).

TABLE III. DESCRIPTIVE StATISTIC OF THE ITEM OF QUeStionNaire

\begin{tabular}{|l|l|l|l|l|l|}
\hline $\begin{array}{l}\text { Items of } \\
\text { questionnaire }\end{array}$ & Alpha $(\boldsymbol{\alpha})$ & Min & Max & Mean & SD \\
\hline PU1 & .894 & 3 & 5 & 4.32 & .568 \\
\hline PU2 & .889 & 3 & 5 & 4.50 & .598 \\
\hline PU3 & .891 & 4 & 5 & 4.68 & .477 \\
\hline PU4 & .884 & 3 & 5 & 4.73 & .550 \\
\hline PE1 & .876 & 3 & 5 & 4.32 & .646 \\
\hline PE2 & .887 & 3 & 5 & 4.09 & .526 \\
\hline PE3 & .890 & 4 & 5 & 4.59 & .503 \\
\hline PE4 & .884 & 4 & 5 & 4.86 & .351 \\
\hline AT1 & .877 & 3 & 5 & 4.18 & .733 \\
\hline AT2 & .886 & 4 & 5 & 4.55 & .510 \\
\hline AT3 & .887 & 4 & 5 & 4.64 & .492 \\
\hline BI1 & .875 & 3 & 5 & 4.14 & .774 \\
\hline BI2 & .881 & 3 & 5 & 4.23 & .685 \\
\hline BI4 & .890 & 3 & 5 & 4.27 & .550 \\
\hline BI5 & .886 & 4 & 5 & 4.59 & .503 \\
\hline SN1 & .877 & 3 & 5 & 4.23 & .685 \\
\hline SN2 & .878 & 3 & 5 & 4.27 & .631 \\
\hline SE1 & .880 & 4 & 5 & 4.45 & .510 \\
\hline SE2 & .884 & 3 & 5 & 4.45 & .671 \\
\hline
\end{tabular}

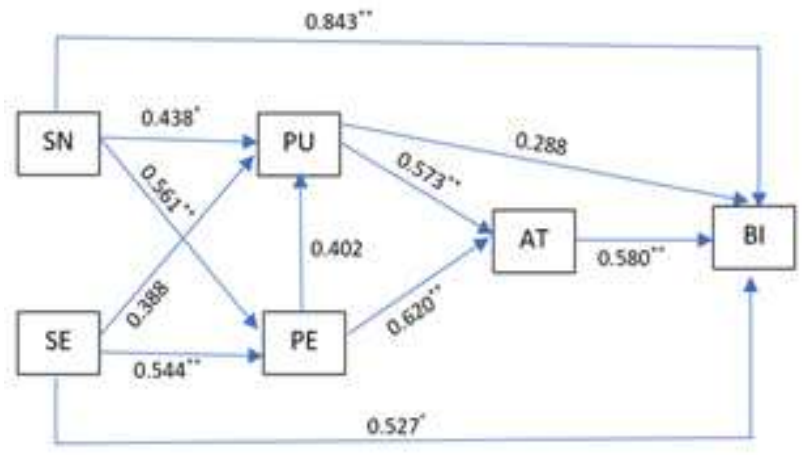

Fig. 2. Correlation between Variables of the Result. 
TABLE IV. CORRELATION BETWEEN VARIABLES

\begin{tabular}{|l|l|c|l|}
\hline Independent variables & $\begin{array}{l}\text { Dependent } \\
\text { Variables }\end{array}$ & $\begin{array}{l}\text { Person } \\
\text { correlation }\end{array}$ & $\boldsymbol{p}$-value \\
\hline PE & PU & 0.402 & 0.064 \\
\hline PE & AT & $0.620^{* *}$ \\
PU & BI & $0.573^{* *}$ & 0.002 \\
\hline PU & PU & $0.580^{* *}$ & 0.005 \\
AT & PE & $0.438^{*}$ & 0.005 \\
\hline SN & BI & $0.561^{* *}$ & 0.042 \\
\hline SN & PU & $0.843^{* *}$ & 0.007 \\
\hline SN & PE & 0.388 & 0.000 \\
\hline SE & BI & $0.544^{* *}$ & 0.074 \\
\hline SE & & $0.527^{*}$ & 0.009 \\
\hline SE & & \\
\hline
\end{tabular}

TABLE V. HYPOTHESES AND REGRESSION SCORES

\begin{tabular}{|c|c|c|c|c|c|c|c|}
\hline The model hypothesis & Independent variables & Dependent variables & B & $\mathbf{t}$ & p-value & $\mathbf{R}$ & $\mathbf{R}^{2}$ \\
\hline $\mathrm{H} 1$ & PE & PU & 0.364 & 1.962 & 0.064 & 0.402 & 0.161 \\
\hline $\mathrm{H} 2$ & $\begin{array}{l}\text { PE } \\
\text { PU }\end{array}$ & AT & $\begin{array}{l}0.372 \\
0.341\end{array}$ & $\begin{array}{l}2.647 \\
2.204\end{array}$ & 0.001 & 0.714 & 0.510 \\
\hline $\mathrm{H} 3$ & $\begin{array}{l}\text { PU } \\
\text { AT }\end{array}$ & $\mathrm{BI}$ & $\begin{array}{l}-0.091 \\
0.965\end{array}$ & $\begin{array}{l}-0.289 \\
2.716\end{array}$ & 0.019 & 0.583 & 0.340 \\
\hline $\mathrm{H} 4$ & $\mathrm{SN}$ & $\mathrm{PU}$ & 0.527 & 2.179 & 0.042 & 0.438 & 0.192 \\
\hline H5 & $\mathrm{SN}$ & PE & 0.745 & 3.029 & 0.007 & 0.561 & 0.314 \\
\hline H6 & SN & BI & 1.400 & 7.007 & 0.000 & 0.843 & 0.710 \\
\hline H7 & SE & $\mathrm{PU}$ & 0.525 & 1.885 & 0.074 & 0.388 & 0.151 \\
\hline $\mathrm{H} 8$ & SE & $\mathrm{PE}$ & 0.813 & 2.903 & 0.009 & 0.544 & 0.296 \\
\hline H9 & SE & $\mathrm{BI}$ & 0.983 & 2.776 & 0.012 & 0.527 & 0.278 \\
\hline
\end{tabular}

Subjective norm (SN) variable were found significant in predicting: $\mathrm{PU}(\mathrm{p}$-value $=0.042<0.05)$; $\mathrm{PE}(\mathrm{p}$-value $=0.007<$ $0.05)$; and also predicting BI ( $\mathrm{p}$-value $=0.000<0.05)$, it means $\mathrm{H} 4, \mathrm{H} 5$ and H6 were accepted. Self-efficacy (SE) variable was found not significant in predicting PU (p-value $=0.074>0.05$ ) means $\mathrm{H} 7$ rejected, but SE were significant in predicting: $\mathrm{PE}$ $(\mathrm{p}$-value $=0.009<0.05) ; \mathrm{BI}(\mathrm{p}$-value $=0.012<0.05)$ means that $\mathrm{H} 8$ and $\mathrm{H} 9$ were accepted. Table $\mathrm{V}$ indicated that out of nine hypotheses two of them were not accepted.

\section{DISCUSSION}

The outcome of this study showed that teachers commonly agree that Lego Mindstorms Ev3 as a learning method was expressed in all questionnaire items averaging greater than 3.0. The perceived ease of use of Lego Mindstorms Ev3 as learning tools has not a positive impact on the perceived usefulness in this study, this is different from what has been written in the literature [13]. This study showed that elementary school teachers gave a positive attitude toward usage (AT) Lego Mindstorm Ev3 because there were relationship between PU and PE; (1) Usage of Lego Mindstorms Ev3 provided benefits to improve productivity, performance, efficiency teachers in classes, and the students were actively involved in the lesson; (2) Lego Mindstorms Ev3 as learning tools were quickly to understand and were easy to operate, this outcome was consistent with previous studies, that educational robotics improved teacher attitudes because robotics improved STEM interaction and teaching [46], The teachers indicated that the use of the Lego WeDo 2.0 robotics kit provides a unique opportunity for computer skills to be developed; it focuses on activities that facilitate problem-solving and group work with primary school students [32]. The relationship between perceived useful and easy to use for technology acceptance has been demonstrated for numerous information technologies [24].

The previous studies explained that attitudes toward teaching assistance robots mainly determined teacher's intended use for the robots [20], the highest positive effect was determined of attitude toward to intention of use of a Telepresence Robot in the classroom by teachers compared with other variables (perceived usefulness, perceived enjoyment, trust of technology, social influence, and gender) [47], it was in accordance with this study indicated that Lego Mindstorms Ev3 as learning tools were attractive, fun, and useful in the learning process had a positive influence on the behavioral intention of the teacher to use Lego Mindstorms in a lesson. 
Furthermore, by emphasizing one of the social factors such as subjective norm, this study showed that organizations and other teachers supported to use of Lego Mindstorms Ev3 in the classroom, subjective norms have a positive correlation with $\mathrm{PU}, \mathrm{PE}$, and $\mathrm{BI}$, this result consists to a previous study that one of important predictors in the robot acceptance model was subjective norm [48].

The teachers' capabilities to organize and use the Lego Mindstorms Ev3 as a self-efficacy variable. Teachers' selfefficacy was not significant in predicting PU; this result was not consistent with a previous study that self-efficacy supported the perceived use [19]. Teacher's self-efficacy were significant in predicting PE and BI, this found consistent with previous study [48] that Perceived ease of use was influenced by self-efficacy (the highest correlation coefficients).

In line with other research; there was a positive correlation between perceived usefulness, perceived ease of use, behavioral intention, and use in human-robot interaction in production systems [48], usefulness and ease of use were predictive of adults' attitudinal acceptance of a domestic robot in their home; ease of use and attitudinal acceptance were predictive of intentional acceptance [24], the teacher beliefs, attitudes and intention to use the software in their future teaching [49], this study found that Lego Mindstorms Ev3 as a learning resource had generated the intention of teachers to use it in their classroom so it had a positive impact on the actual use of teachers.

\section{CONCLUSION}

This study showed that the two factors of the TAM model, perceived usefulness and perceived ease to use had generated the positive attitude use of Lego Mindstorms Ev3 as learning tools by elementary school teachers, it also had a positive effect on behavior intentions, and finally, all of the variables gave support to the actual use of Lego Mindstorms Ev3 as learning tools in learning-process in elementary school.

\section{LIMITATION AND RECOMMENDATION FOR FUTURE WORK}

The limitations of this study: the sample size was small because it was taken from workshop participants in the introduction of robotics technology to elementary school teachers; the workshops were carried out in limited time, just 2 days, much better if we extended the duration of the workshops; the teacher was directly involved in actively interacting with Lego Mindstorms Ev3 as learning tools in the workshop but still needed adjustments at the initial stage of using Lego Mindstorms Ev3 considering that robotic technology was one of the technological trends in the 4.0 revolution era.

TAM has developed itself as a strong and robust model for explaining technical comprehension, like other theoretical frameworks. For future studies, it is necessary to develop the original model of TAM by taking into account other external variables that have an effect on the intention to use or actual use of Lego Mindstorms Ev3 in the classroom such as educational background, school facilities, gender, age, and others.
This study provides a view of teachers' acceptance of the Lego Mindstorms Ev3 in the learning process in their classroom to increase effectiveness and quality of education. This study could suggest to the elementary schools to develop learning tools based on technology, and always updating the technology will be applied in education.

\section{ACKNOWLEDGMENT}

This research was supported by LLDIKTI from The Ministry of Research and Technology to fund this research through the "Penelitian Strategis Nasional Institusi (PSNI)" program.

\section{REFERENCES}

[1] L. Stošić, "The importance of educational technology in teaching," Int. J. Cogn. Res. Sci. Eng. Educ., vol. 3, no. 1, pp. 111-114, 2015.

[2] S. Ghavifekr and W. A. W. Rosdy, "Teaching and learning with technology: Effectiveness of ICT integration in schools," Int. J. Res. Educ. Sci., vol. 1, no. 2, pp. 175-191, 2015.

[3] B. Hendrik, N. M. Ali, and N. M. Nayan, "Robotic Technology for Figural Creativity Enhancement: Case Study on Elementary School," Int. J. Adv. Comput. Sci. Appl., vol. 11, no. 1, pp. 536-543, 2020.

[4] M. Masril et al., "The Effect of Lego Mindstorms as an Innovative Educational Tool to Develop Students' Creativity Skills for a Creative Society," J. Phys. Conf. Ser., vol. 1339, no. 1, 2019.

[5] S. B. Kert, M. F. Erkoç, and S. Yeni, "The effect of robotics on six graders' academic achievement, computational thinking skills and conceptual knowledge levels," Think. Ski. Creat., vol. 38, no. March, p. 100714, 2020.

[6] F. B. V. Benitti, "Exploring the educational potential of robotics in schools: A systematic review," Comput. Educ., vol. 58, no. 3, pp. 978988, 2012.

[7] C. Oranç and A. C. Küntay, "Children's perception of social robots as a source of information across different domains of knowledge," Cogn. Dev., vol. 54, no. March, p. 100875, 2020.

[8] A. Edwards, C. Edwards, P. R. Spence, C. Harris, and A. Gambino, "Robots in the classroom: Differences in students' perceptions of credibility and learning between 'teacher as robot' and 'robot as teacher," Comput. Human Behav., vol. 65, pp. 627-634, 2016.

[9] R. Szczepanowski et al., "Education biases perception of social robots," Rev. Eur. Psychol. Appl., vol. 70, no. 2, 2020.

[10] M. Chevalier, F. Riedo, and F. Mondada, "How do teachers perceive educational robots in formal education? A study based on the Thymio robot* Thymio BeeBot Finch," Ieeexplore.Ieee.Org, 2014.

[11] G. Mqawass, "Students' Perceptions and Acceptance of lego Robots in Syria," J. Interrupted Stud., vol. 1, no. 1, pp. 26-33, 2018.

[12] E. Z. F. Liu, "Early adolescents' perceptions of educational robots and learning of robotics," Br. J. Educ. Technol., vol. 41, no. 3, pp. 44-47, 2010.

[13] A. H. K. Yuen and W. W. K. Ma, "Exploring teacher acceptance of elearning technology," Asia-Pacific J. Teach. Educ., vol. 36, no. 3, pp. 229-243, 2008.

[14] W. W. Goh, J. L. Hong, and W. Gunawan, "Exploring students' perceptions of learning management system: An empirical study based on TAM," Proc. 2013 IEEE Int. Conf. Teaching, Assess. Learn. Eng. TALE 2013, pp. 367-372, 2013.

[15] W. Daher, J. Abu-Hussein, and E. Alfahel, “Teachers' perceptions of interactive boards for teaching and learning in public and private high schools in the arab education system in israel," Int. J. Emerg. Technol. Learn., vol. 7, no. 1, pp. 10-18, 2012.

[16] C. Buabeng-Andoh, "Factors influencing teachers ' adoption and integration of information and communication technology into teaching: A review of the literature," Int. J. Educ. Dev. Using Inf. Commun. Technol., vol. 8, no. 1, pp. 136-155, 2012.

[17] C. M. Khee, G. W. Wei, and S. A. Jamaluddin, "Students' Perception towards Lecture Capture based on the Technology Acceptance Model," 
Procedia - Soc. Behav. Sci., vol. 123, pp. 461-469, 2014.

[18] L. D. Prasojo, A. Habibi, A. Mukminin, Sofyan, B. Indrayana, and K. Anwar, "Factors influencing intention to use web 2.0 in Indonesian vocational high schools," Int. J. Emerg. Technol. Learn., vol. 15, no. 5, pp. 100-118, 2020.

[19] A. Aypay, H. C. Çelik, A. Aypay, and M. Sever, "Technology acceptance in education: A study of pre-service teachers in Turkey," Turkish Online J. Educ. Technol., vol. 11, no. 4, pp. 264-272, 2012.

[20] E. Park and S. J. Kwon, "The Adoption of Teaching Assistant Robots : A Technology Acceptance Model Approach," Emerald Gr., 2016.

[21] F. George and M. Ogunniyi, "Teachers' Perceptions on the Use of ICT in a CAL Environment to Enhance the Conception of Science Concepts," Univers. J. Educ. Res., vol. 4, no. 1, pp. 151-156, 2016.

[22] M. M. A. De Graaf and S. Ben Allouch, "Exploring influencing variables for the acceptance of social robots," Rob. Auton. Syst., vol. 61, no. 12, pp. 1476-1486, 2013.

[23] D. Pal and S. Patra, "University Students' Perception of Video-Based Learning in Times of COVID-19: A TAM/TTF Perspective," Int. J. Hum. Comput. Interact., vol. 00, no. 00, pp. 1-19, 2020.

[24] N. Ezer, A. D. Fisk, and W. A. Rogers, "Attitudinal and intentional acceptance of domestic robots by younger and older adults," Lect. Notes Comput. Sci. (including Subser. Lect. Notes Artif. Intell. Lect. Notes Bioinformatics), vol. 5615 LNCS, no. PART 2, pp. 39-48, 2009.

[25] D. H. Shin and H. Choo, "Modeling the acceptance of socially interactive robotics: Social presence in human-robot interaction," Interact. Stud., vol. 12, no. 3, pp. 430-460, 2011.

[26] Z. Hussein, "Leading to Intention: The Role of Attitude in Relation to Technology Acceptance Model in E-Learning," Procedia Comput. Sci., vol. 105, no. December 2016, pp. 159-164, 2017.

[27] S. Alharbi and S. Drew, "Using the Technology Acceptance Model in Understanding Academics' Behavioural Intention to Use Learning Management Systems," Int. J. Adv. Comput. Sci. Appl., vol. 5, no. 1, 2014.

[28] C. Bröhl, J. Nelles, C. Brandl, A. Mertens, and C. M. Schlick, "TAM reloaded: A technology acceptance model for human-robot cooperation in production systems," Commun. Comput. Inf. Sci., vol. 617, no. March 2017, pp. 97-103, 2016.

[29] R. Alotaibi, L. Houghton, and K. Sandhu, "Factors Influencing Users' Intentions to Use Mobile Government Applications in Saudi Arabia: TAM Applicability,” Int. J. Adv. Comput. Sci. Appl., vol. 8, no. 7, pp. 200-211, 2017.

[30] A. Kim, J. Han, Y. Jung, and K. Lee, "The effects of familiarity and robot gesture on user acceptance of information," ACM/IEEE Int. Conf. Human-Robot Interact., pp. 159-160, 2013.

[31] T. I. Ensign, "Elementary Educators' Attitudes about the Utility of Educational Robotics and Their Ability and Intent to Use It with Students," 2017.

[32] C. Chalmers, "Robotics and computational thinking in primary school," Int. J. Child-Computer Interact., vol. 17, 2018.

[33] N. Reich-Stiebert and E. Friederike, "Robots in the Classroom: What Teachers Think About Teaching and Learning with Education Robots," Soc. Robot., vol. 9979 LNAI, pp. 671-680, 2016.

[34] N. N. Long and B. H. Khoi, "The Intention to Study Using Zoom During the SARS-CoV-2 Pandemic," Int. J. Emerg. Technol. Learn., vol. 15, no. 21, p. 195, 2020.
[35] A. S. Ghazali, J. Ham, E. Barakova, and P. Markopoulos, "Persuasive Robots Acceptance Model (PRAM): Roles of Social Responses Within the Acceptance Model of Persuasive Robots," Int. J. Soc. Robot., vol. 12, no. 5, pp. 1075-1092, 2020.

[36] R. Nadlifatin, B. Ardiansyahmiraja, and S. F. Persada, "The measurement of university students' intention to use blended learning system through technology acceptance model (tam) and theory of planned behavior (TPB) at developed and developing regions: Lessons learned from Taiwan and Indonesia,” Int. J. Emerg. Technol. Learn., vol. 15, no. 9, pp. 219-230, 2020.

[37] A. R. D. E. R. Pütten and N. Bock, "Development and Validation of the Self-Efficacy in Human-Robot-Interaction Scale ( SE-HRI )," ACM Trans. Human-Robot Interact., vol. 7, no. 3, 2018.

[38] L. Huang, T. Varnado, and D. Gillan, "Exploring reflection journals and self-efficacy in robotics education," Proc. Hum. Factors Ergon. Soc., vol. 2014-Janua, pp. 1939-1943, 2014.

[39] R. Latikka, T. Turja, and A. Oksanen, "Self-efficacy and acceptance of robots," Comput. Human Behav., vol. 93, pp. 157-163, 2019.

[40] N. L. Robinson, T. N. Hicks, G. Suddrey, and D. J. Kavanagh, "The Robot Self-Efficacy Scale: Robot Self-Efficacy, Likability and Willingness to Interact Increases after a Robot-Delivered Tutorial," 29th IEEE Int. Conf. Robot Hum. Interact. Commun. RO-MAN 2020, pp. 272-277, 2020.

[41] K. G. Tileng, "Penerapan Technology Acceptance Model Pada Aplikasi Edmodo di Universitas Ciputra Surabaya Menggunakan Analisis Jalur," Juisi, vol. 01, no. 01, pp. 28-37, 2015.

[42] S. A. Filippov, A. L. Fradkov, and B. Andrievsky, Teaching of robotics and control jointly in the university and in the high school based on LEGO Mindstorms NXT, vol. 44, no. 1 PART 1. IFAC, 2011.

[43] J. Chetty, "Lego (C) Mindstorms: Merely a Toy or a Powerful Pedagogical Tool for Learning Computer Programming ?," Proc. 38th Australas. Comput. Sci. Conf. (ACSC 2015), no. January, pp. 27-30, 2015.

[44] F. D. Davis, "Perceived usefulness, perceived ease of use, and user acceptance of information technology," MIS Q. Manag. Inf. Syst., vol. 13, no. 3, pp. 319-339, 1989.

[45] B. Çukurbaşı, G. Yavuz Konokman, B. Güler, and S. Kartal, "Developing The Acceptance Scale Of LEGO Robotics Instructional Practices: Validity And Reliability Studies," Bartın Üniversitesi Eğitim Fakültesi Derg., vol. 7, no. 1, pp. 191-214, 2018.

[46] C. Kim, D. Kim, J. Yuan, R. B. Hill, P. Doshi, and C. N. Thai, "Robotics to promote elementary education pre-service teachers' STEM engagement, learning, and teaching," Comput. Educ., vol. 91, pp. 14-31, 2015.

[47] J. Han and D. Conti, "The use of UTAUT and post acceptance models to investigate the attitude towards a telepresence robot in an educational setting," Robotics, vol. 9, no. 2, 2020.

[48] C. Bröhl, J. Nelles, C. Brandl, A. Mertens, and V. Nitsch, "HumanRobot Collaboration Acceptance Model: Development and Comparison for Germany, Japan, China and the USA," Int. J. Soc. Robot., vol. 11, no. 5, pp. 709-726, 2019.

[49] I. M. Santos, N. Ali, M. S. Khine, A. Hill, U. Abdelghani, and K. A. Al Qahtani, "Teacher perceptions of training and intention to use robotics," IEEE Glob. Eng. Educ. Conf. EDUCON, vol. 10-13-Apri, no. April, pp. 798-801, 2016. 
APPENDIX A. QUESTIONNAIRE DETAILS USED IN THE SURVEY

\begin{tabular}{|c|c|c|c|}
\hline Construct & Items & Item wordings & Reference \\
\hline \multirow{4}{*}{ Perceived to Used } & PU1 & Using Lego Mindstorms Ev3 increases my productivity in classes & \multirow{4}{*}{$\begin{array}{l}{[44]} \\
{[45]}\end{array}$} \\
\hline & PU2 & Using Lego Mindstorms Ev3 increases my performance in classes & \\
\hline & PU3 & Using Lego Mindstorms Ev3 increases my efficiency in classes & \\
\hline & PU4 & I think that using Lego Mindstorms Ev3 is useful for activities related to my school life & \\
\hline \multirow{4}{*}{ Perceived ease to used } & PE1 & I find it easy to learn Lego Mindstorms Ev3 applications & \multirow{4}{*}{ [45] } \\
\hline & PE2 & I easily teach lessons with Lego Mindstorms Ev3 practices & \\
\hline & PE3 & $\begin{array}{l}\text { The steps that I have to take to solve any problem in Lego Mindstorms Ev3 practice are } \\
\text { clear and comprehensible }\end{array}$ & \\
\hline & PE4 & I think I will easily master Lego Mindstorms Ev3 practices & \\
\hline \multirow{3}{*}{ Attitude toward used } & AT1 & It would be fun to do Lego Mindstorms Ev3 practices in my classes & \multirow{3}{*}{ [45] } \\
\hline & AT2 & I would enjoy doing Lego Mindstorms Ev3 practices in my classes & \\
\hline & AT3 & It would make me happy to do Lego Mindstorms Ev3 practices in my classes & \\
\hline \multirow{4}{*}{ Behavioral Intention to Use } & BI1 & I want to do Lego Mindstorms Ev3 practices in my classes & \multirow{4}{*}{ [45] } \\
\hline & BI2 & I Would like to do Lego Mindstorms Ev3 practices in my future classes & \\
\hline & $\mathrm{BI} 3$ & I will encourage my colleagues to do Lego Mindstorms Ev3 practices & \\
\hline & $\mathrm{BI} 4$ & I will include Lego Mindstorms Ev3 practices in my education and teaching career & \\
\hline \multirow{2}{*}{ Self-Efficacy } & SE1 & I can use the Lego Mindstorms Ev3, if someone shows me how to do it first & \multirow{2}{*}{$\begin{array}{l}{[28]} \\
{[13]}\end{array}$} \\
\hline & SE2 & I can use the Lego Mindstorms Ev3, if I had only the manual book for reference & \\
\hline \multirow[b]{2}{*}{ Subjective Norm } & SN1 & In general, the organization supports the use of the Lego Mindstorms Ev3 & \multirow{2}{*}{$\begin{array}{l}{[28]} \\
{[36]}\end{array}$} \\
\hline & SN2 & $\begin{array}{l}\text { those people who are important to me would strongly support my using Lego } \\
\text { Mindstorms Ev3 in my classroom }\end{array}$ & \\
\hline
\end{tabular}

